\title{
GCU
}

Glasgow Caledonian

University

University for the Common Good

\section{Collision avoidance head-up display: design considerations for emergency services' vehicles}

Bram-Larbi, Kweku; Charissis, Vassilis; Harrison, David; Khan, Mohammed Soheeb; Lagoo, Ramesh; Drikakis, Dimitris

Published in:

2020 IEEE International Conference on Consumer Electronics (ICCE)

DOI:

10.1109/ICCE46568.2020.9043068

Publication date:

2020

Document Version

Author accepted manuscript

Link to publication in ResearchOnline

Citation for published version (Harvard):

Bram-Larbi, K, Charissis, V, Harrison, D, Khan, MS, Lagoo, R \& Drikakis, D 2020, Collision avoidance head-up display: design considerations for emergency services' vehicles. in 2020 IEEE International Conference on Consumer Electronics (ICCE). IEEE, pp. 1-7, IEEE International Conference on Consumer Electronics (ICCE), Las Vegas, Nevada, United States, 4/10/19. https://doi.org/10.1109/ICCE46568.2020.9043068

\section{General rights}

Copyright and moral rights for the publications made accessible in the public portal are retained by the authors and/or other copyright owners and it is a condition of accessing publications that users recognise and abide by the legal requirements associated with these rights.

Take down policy

If you believe that this document breaches copyright please view our takedown policy at https://edshare.gcu.ac.uk/id/eprint/5179 for details of how to contact us. 


\title{
Collision Avoidance Head-Up Display: Design Considerations for Emergency Services’ Vehicles
}

\author{
K.F. BRAM-LARBI ${ }^{1}$, V. CHARISSIS ${ }^{1}$, S. KHAN ${ }^{1}$, R. LAGOO $^{1}$, D. K. HARRISON ${ }^{1}$ and D. DRIKAKIS ${ }^{2}$ \\ ${ }^{1}$ Glasgow Caledonian University, Glasgow, UK \\ School of Computing, Engineering and Built Environment \\ ${ }^{2}$ University of Nicosia, Nicosia, Cyprus \\ School of Sciences and Engineering
}

\begin{abstract}
Emergency Services' (ES) vehicles primary objective is to attend accident or other incident scenes in a fast, safe and efficient manner. Yet this task is becoming increasingly difficult due to the increasing population and the plethora of emergency cases. These factors affect directly the traffic both within the urban and the rural environment, decreasing dramatically the time to arrive at the point of interest. Numerous Head-Down Display (HDD) systems have populated the dashboard area of the ES vehicles in order to tackle this issue, with limited success. To this end, the development of emerging technologies in both computing and telecommunications have enabled modern vehicular systems to assist drivers in their decision-making process. Head-Up Displays (HUD) present a combinatory approach of the aforementioned technologies, which present crucial information to the driver through Augmented Reality (AR) projection. In order to develop a design and development framework for the utilisation of AR and HUD technology, this paper presents the results of 50 drivers investigation related to their activities during immobile or slow-moving traffic which results in driver's distraction and inability to respond to the incoming ES vehicles. In turn, the paper discusses these results and offers an overview of the Human-Machine Interface requirements for a prototype HUD aiming to assist the safety, speed and manoeuvrability of the ES vehicles.
\end{abstract}

Keywords - Emergency Response Vehicles, Head-Up Display, Collision Avoidance, Augmented Reality, Driver Distraction, Driving Simulator

\section{INTRODUCTION}

Emergency Services (ES), entailing ambulance, police and fire-brigade services, play a vital role in ensuring that citizens in-need receive support and treatment efficiently and in a timely manner $[1,2]$. The latter though could be greatly affected by a number of variables hindering the speed of support provided by the ES vehicles. On a number of occasions, journeys expected to take eight minutes or less were extended up to three hours before ES staff could attend the incidents [3]. In some parts of the world, the deplorable condition of the roads makes it almost impossible for ES to gain access to, or transport the patients [3]. Navigation through traffic can be a major problem for ES drivers. In their effort to counteract the traffic and road conditions, ambulance drivers face a great risk of collision, not only from on-coming traffic, since they are sometimes required to drive in the opposite lane when there is stagnant traffic, but also collision into inattentive vehicles and pedestrians, especially in not so favourable weather conditions.

Taking the aforementioned into account, being able to perform such important tasks within such a short time span, will require a great amount of speed and precision on the part of ES personnel. Emergency vehicles' response speed is crucial to clinical outcomes in serious cases. The successful patient transfer is directly related to the speed that the rescue vehicle can achieve through the traffic flow, particularly in traffic congestion bottlenecks [4].

This paper identifies the major issues related to ES vehicles' delays and collisions and offers a framework for an alternative solution that aims to enhance ES drivers' human responses in high speed and manoeuvring through traffic.

In order to inform the proposed system design, this work investigates the questionnaire responses of 50 drivers related to their activities during immobile or slow-moving traffic which results in driver's distraction and inability to respond to the incoming ES vehicles. Their responses, in turn, inform the design requirements of the proposed system which employs an Augmented Reality (AR) Head-Up Display (HUD). The latter assumes interface design mantra and methodology from our previous HUD interfaces designed for navigation and collision avoidance purposes [5, $6 \& 7]$.

The following section presents the current ES navigation issues. The succeeding section investigates the drivers' failure to maintain spatial and situational awareness in slow or immobile traffic which hinders the ES vehicles manoeuvring through the traffic. The third section discusses the system design requirements, challenges and proposed solutions. Finally, the paper concludes with a succinct review of the potential design considerations based on the feedback from 50 drivers' informing the future development of the interface components for the ES HUD. 


\section{Current ES Navigation Issues}

Contemporary navigation systems promise to improve driving performance by presenting an optimal route with respect to reducing travel time and or improving fuel consumption. Hence, they function solely as route calculation machines which affect the singular aspect of the driving experience, namely spatial orientation [6,7]. Such systems, however, do not support or improve drivers' spatial and situational awareness, that is primarily responsible for most collisions $[5,6,8]$. The current navigation issues for ES vehicles' navigation issues discussed within this paper can be attributed to the following factors.

\section{A. Siren Localisation Issues}

Sound can be the first warning perceivable by human senses of events that are taking place beyond the human field of view. Unlike vision, which can be obscured by buildings and other objects, the sound is perceptible from multiple directions.

Thus, auditory information is vital for situation awareness on the roads, both as complementary and supplementary to vision [4]. Consequently, audible warning systems are integral to emergency vehicles to allow them to be located by other motorists and pedestrians $[7,8]$.

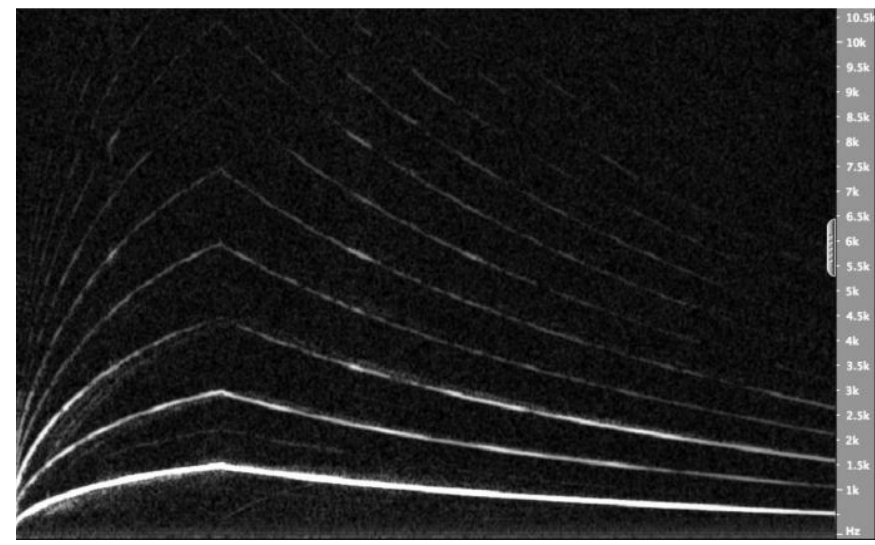

Fig. 1. Typical sweeping siren pattern as described by Moore et al. 2011 [9].

However, hearing a sound does not always provide enough information to determine the exact direction from which this sound occurred or is occurring, especially when this sound is in constant disarray of high pitch volume.

Notably, ES sirens typically employ a sweeping pattern with most of the sound energy located in the region of $500 \mathrm{~Hz}$ to $1500 \mathrm{~Hz}$ as depicted in Figure 1 [9].

Yet, it has been documented that the localisation characteristics of existing siren patterns combined with high levels of background noise can significantly affect the average driver's ability to accurately define the position and heading direction of the incoming emergency vehicle $[4,9]$. Evidently, the human inability to accurately locate the direction of an approaching emergency vehicle is directly linked to the siren patterns themselves $[10,11]$. This spatial misjudgment contributes to multiple fatalities and casualties according to the British road accident statistics [12].

A previous investigation into audible warning systems showed that sirens were used $86 \%$ of the time by ES vehicles when on call, but this was not always in unison with warning lights [13]. In this survey that examined public reactions to the audible warning, the results showed that nearly one-third of drivers failed to detect the approaching emergency vehicle until it was less than $50 \mathrm{~m}$ away. Interestingly, $25 \%$ of the participants were completely unable to hear the audible warning systems on the approach of the emergency vehicle. These figures reinforce the limited effectiveness of current emergency vehicle audible warning systems [11,13].

Aiming to mitigate this issue, previous studies have explored the current possibilities regarding the types of technology used to avert collisions on the part of the emergency response services [5,6]. In relation to the ES drivers, even with the intervention of RDS (Radio Data System), which also help in traffic situations, collision avoidance is still a prominent issue.

\section{B. Driver Distraction}

The drivers' inability to locate the sound source on multiple occasions is not only an issue of sound propagation. A number of other reasons could be contributory as presented below:

- Driver's age - Older drivers have naturally dampened senses which affect their spatial and situational awareness.

- Infotainment Distraction - One of the most common issues is driver distraction due to the vehicular infotainment systems. The latter is typically providing a plethora of information based on mobile phone communication, navigation, music, various applications in the form of social media and the full access to internet resources. The aforementioned infotainment resources have a detrimental impact on the driver's cognitive load and as a result, reduce dramatically the spatial and situational awareness [16 Ram].

- Passengers' Distraction - Similarly, the driver could be distracted by the passengers as it was observed by previous studies $[14,15]$.

-Vehicle's sound system - In addition, the loud volume of the vehicle's sound system could render the driver effectively deaf to any external sounds.

- Vehicle's soundproofing - The above cases could be further amplified by the soundproofing of modern vehicles which aim to enclose the vehicle occupants in a relaxing space detached from the external traffic noises. 


\section{ES Vehicles' Head-Down Displays (HDD)}

Some of the aforementioned driver distractions tend to affect also the ES vehicle drivers. In their case, the information provided by multiple conduits regarding navigation, traffic and accident scene data could increase significantly the cognitive load. The attention to the traffic conditions could further deteriorate as the focus of the ES driver is to maintain a multi-fold approach ensuring the safety of the ES vehicle occupants (i.e. ES personnel and patients in ambulance cases), identify optimal manoeuvring through traffic, maintain an acceptable high speed and circumvent obstacles whilst ensuring the safety of the neighbouring civilian vehicles.

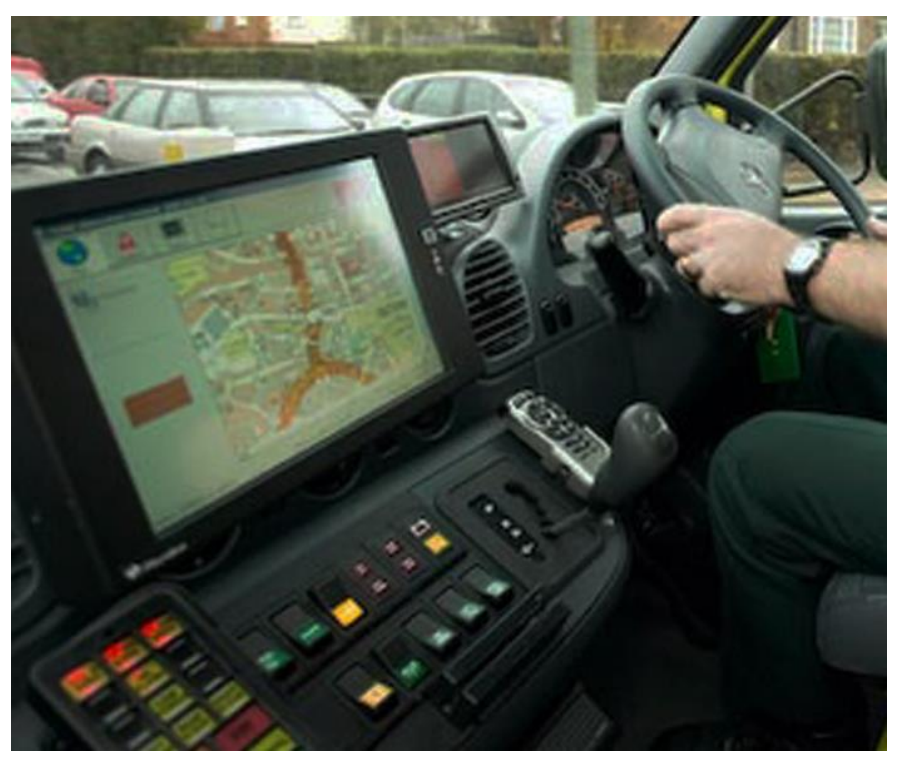

Fig. 2. ES vehicle cabin offering multiple information-provision conduits.

However, this on-road unilaterally biased focus is plagued with many in-vehicle distractions. Current technological advancement and ES requirements tend to over-populate the in-vehicle space in close proximity to the driver, which accommodates the vehicles' infotainment system and provides multiple attention-seeking visual and auditory data $[6,16]$. Notably, the majority of the information-provision is presented to the driver through devices located at the dashboard, below the driver's field of view namely Head-Down Displays (HDD) depicted in Figure 2. Evidently, these mind-sharing notifications could affect the driver's attention, discerning the challenging road-traffic flow [5, 7]. In turn, the HDD interfaces aiming to support the speed and safety of the ES vehicles may not effectively provide critical information any more as the driver's attention may be distributed along with several irrelevant information outlets $[5,17]$. Therefore, in a typical accident scenario in which the lead vehicles brake abruptly, the driver does not have the required time and situational awareness to proceed in a collision avoidance braking manoeuvre [6, 7].

\section{High Speed and Manoeuvring}

In many countries, ambulances are granted several exceptions to road traffic laws aiming to provide them with ample choices under stressful and demanding traffic conditions. As such, no statutory provision imposing a speed limit, or traffic flow limits apply to ES vehicles [18]. Nonetheless, the selective suspension of particular road traffic laws have limited impact on the actual speed and manoeuvring efficiency of the ES vehicles as the decision making process is primarily provided by the emergency vehicle driver taking into account the relations among speed, collision risk and the need for a fast response [19]. Regardless of the rigorous training of the ES drivers, the multiple variables occurring during high-speed manoeuvring amplify the role of human factors. Yet the decision-making process of the ES drivers is constantly redefined based on the neighbouring vehicles' drivers activities and their ability to respond accordingly to the situation. Speed, although an important factor in the time-sensitive ES response time, is not the main factor that defines the successful arrival to the accident scene [20]. Spasmodic peaks of high-speed between traffic gaps could increase the probability of collisions $[6,10,20]$. Previous work observed that maintaining a constant flow through different driving conditions in medium speed and informing the driver in advance regarding potential traffic issues, could improve both the safety and the time of arrival to the required destination [5]. Thus, maintaining the flow and speed momentum could be a challenge in a real-life, non-deterministic road-traffic. In this case, additional support and provision of information could be employed in a timely manner and with minimal cognitive load requirements to the driver through a combinatory approach of AI / HUD [21, 22].

\section{E. Non-Deterministic Traffic Flow}

In contemporary urban and rural environment, traffic congestion has increased exponentially in the last few decades. Traffic congestion, defined as a performance of traffic flow instability, manifested through ease and inhibition of traffic congestion are equivalent to reducing traffic flow instability. Traffic flow includes many aspects such as road traffic flow, network traffic flow, vehicle traffic flow and the pedestrian traffic flow among others. The modern road vehicle traffic flow models can be categorised into macroscopic, mesoscopic and microscopic traffic flow models all with different benefits and drawbacks. In particular, the microscopic traffic flow model investigates the characteristics of the traffic flow by dealing with traffic flow as dispersed particles and studying the effect of single vehicles on the following vehicles. Its advantages are that it can analyse the transitions and the separation of the traffic flow phase and describe various traffic waves, which is a major issue for the ES vehicles [24, 25]. 


\section{ES VEHICLE DRIVERS}

A preliminary consultation with a focus group of 5 ES vehicle drivers offered an insight into the emergency vehicles' traffic navigation issues.

A number of new technologies such as Traffic Surveillance Technology, Mayday and Automatic Collision Notification Systems have improved this task. Yet other technologies currently available are not directly applicable such as Dynamic (Changeable) Message Signs, due to variations of the road-infrastructure capabilities.

However, the civilian drivers' reduced attendance to the rapidly changing traffic conditions was highlighted as the most impactful on the safety and speed operation of the ERS vehicles. Consequently, this influences the time-bound limitations in which the ES personnel is required to reach an accident and emergency scene. These suggestions were in accordance with the previous studies related to the distance that could be covered by ES in a given time frame [4, 9].

To this end, a proposed solution which will entail the provision of real-time manoeuvring options (AI) directly presented on the real-life scene (HUD) was considered ideal by the ES focus group. In order to determine the exact operation and interface design of such a system, it was deemed essential to identify also the civilian drivers' needs and behaviour whilst populating traffic congestion and identify the reasons behind their decision-making process or their inability to respond to external stimuli.

\section{DRIVERS' ATTENTION AND TRAFFIC ISSUES}

The majority of the aforementioned issues that have a negative impact on the timely and safe provision of ES is due to the human factors involved. Adhering to the above, this work aims to identify not only the ES drivers' current navigation issues but also the civilian drivers' response capability and time to an incoming ES vehicle. The latter delayed response times disrupt the speed and manoeuvring of the ES vehicles.

\section{A. Questionnaire Design}

The drivers' feedback and requirements were gathered using at this stage primarily qualitative data analysis and grounded theory-based research study [26]. The questionnaire entailed 25 questions and was formed in two parts.

The first part gathered drivers' demographic information as well as the number of miles driven annually, type of road-network mostly used and frequency of encounters with ERS vehicles that need priority on the road.

The second part of the questionnaire (20 questions) was designed to retrieve the drivers' responses regarding their driving behaviour and habits in slow-moving or immobile traffic conditions. The interest on the latter is that the drivers tend to occupy themselves with numerous infotainment systems and applications either following a steady, dense, traffic flow or waiting for the traffic gridlock resolution. Consequently, the drivers' can be distracted from the surrounding environment and unintentionally disregard both the siren and the lights from approaching ES vehicles [6].

\section{B. Participants}

The investigation was performed with the use of 50 participants (40 male and 10 female), which all held a valid British driving licence. The participants' age was spanning from 18 to 60 years old.

\section{STUdy Results}

The results derived from 18 selected questions targeting the drivers' behavioural issues that hinder current ES and could pose a danger to the overall traffic flow are presented below.

In particular, $34 \%$ of the 50 drivers admitted that they send messages (very frequently, often, sometimes) whilst driving as illustrated in Figure 3. An alarming 60\% of the drivers responded that they read mobile phone text messages while driving.

Adhering to previous studies related to mobile phone calls and texting, the driver's attention is fully diminished during these tasks which typically result in collision accidents [6,27]. In addition, the drivers' response to the usage of navigation systems is $76 \%$ whilst internet usage whilst driving was $40 \%$.

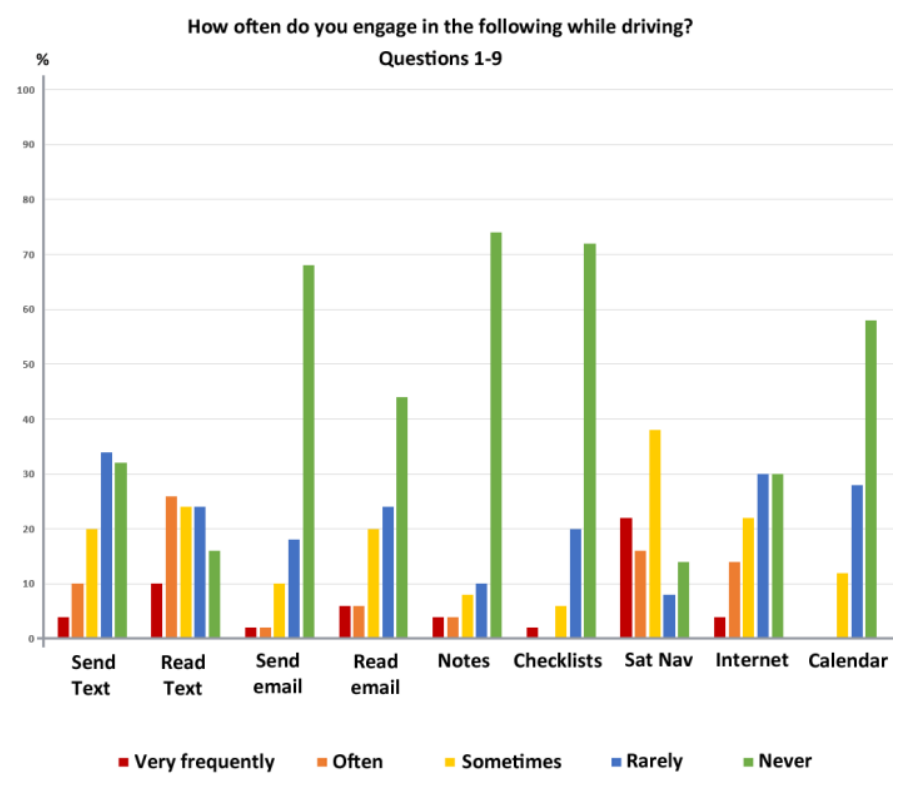

Fig. 3. How often do you engage in the following while driving? Responses to questions 1-9.

Smaller percentages were encountered in reading/writing notes (16\%) and checklists (8\%). 
The drivers that responded to those questions were using driving as part of their work such as construction workers and parcel delivery staff which are an increasing group of users due to the emerging Gig economy globally [28].

Calendar and daily events' information received $12 \%$ of interaction (sometimes).

Music, as expected, received the highest percentage of interaction during driving with $90 \%$, which in a number of cases relates also to the inability of the driver to hear the incoming ES vehicles. Thus, the selection process of music through various devices could absorb completely driver's attention from the external environment [6].

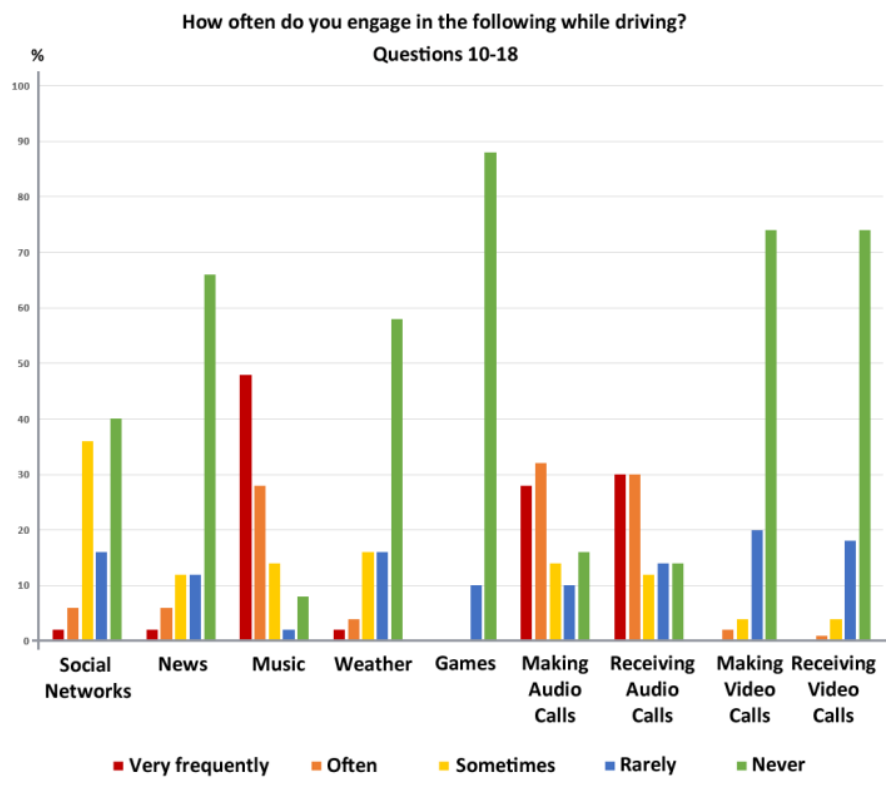

Fig. 4. How often do you engage in the following while driving? Responses to questions 10-18.

Making and Receiving audio calls appeared to score also highly on drivers' secondary activities within the vehicle with $75 \%$ and $80 \%$ respectively as presented in Figure 4. In contrast, the Making and Receiving video calls had limited driver attention with $6 \%$ and $5 \%$ respectively. News' updates were also in moderate scale with $20 \%$.

The upcoming trend though appears with Social Networks with $40 \%$ responding that they use, which reflects the current tendency of a number of automotive manufacturers to include these applications in the main dashboard- touchscreen menu.

\section{AR HUD DESIGN FRAMEWORK}

The aforementioned results highlighted the necessity of a system that could accommodate current ES requirements whilst predicting neighbouring vehicles actions.

A. It is evident that the typical siren and flashing lights are inefficient for a growing segment of drivers' population. These typical warning methods could be improved and complemented by an Emergency Vehicle to Civilian Vehicle (EV to CV) warning which could disrupt/pause any infotainment

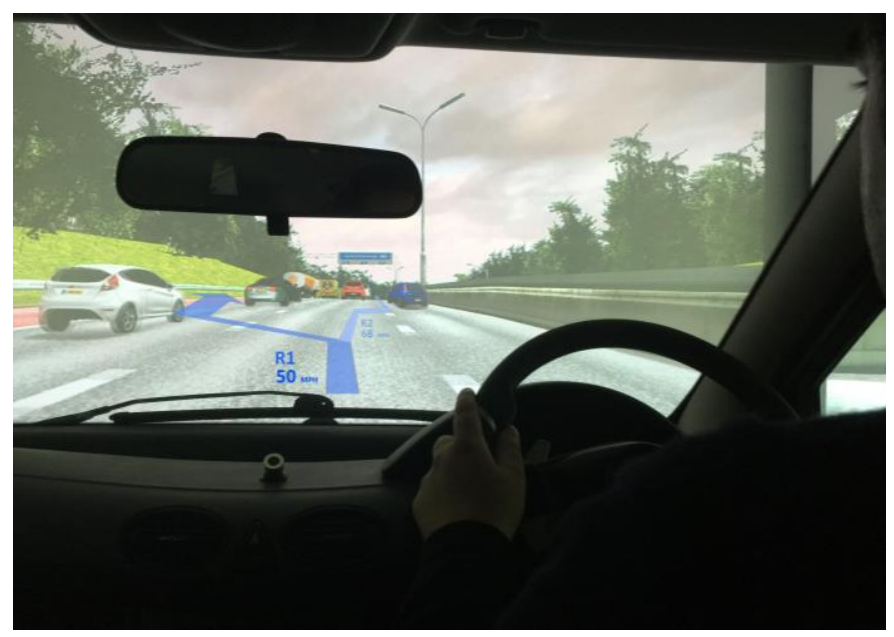

Fig. 5. Screenshot of HUD prototype testing in the Virtual Reality Driving Simulator Laboratory.

broadcasting and application in close proximity to the incoming ERS vehicle. Previous studies investigated the options of RDS yet due to the new technologies embedded on the current vehicles a more holistic approach is required in order to cover the majority of the current infotainment systems [ Boslem].

$B$. Additionally, an AI system will require training on different traffic scenarios and driver responses in order to provide relevant suggestions and alternatives to the ES driver.

$C$. A full-windshield HUD interface could provide real-time AR visualisation of the proposed AI routes, supporting further the driver's decision- making process [7, 29, 30]. An early prototype HUD based on the information provided by both ES and civilian vehicles' drivers is illustrated in Figure 5.

\section{CONCLUSIONS}

This paper presented the main results of a 50 user investigation regarding their driving behaviours whilst in slow-moving or immobile traffic congestion. In turn, the drivers' behaviours tendencies informed the design framework for the development of a prototype AR - HUD interface for the ES vehicle drivers.

The latter will be designed to provide alternative navigation options and manoeuvring possibilities superimposed on the external environment as a full-windshield AR projection. in real time for the ERS vehicle drivers.

In future work, this project aims to finalise the design and interactivity of the proposed HUD interface based on the latest subjective feedback. Finally, the consumer-ready HUD system will be evaluated by the ERS drivers in order to identify the system efficiency. 


\section{REFERENCES}

[1] N. Smith, "A National Perspective on Ambulance Crashes and Safety: Guidance from the National Highway Traffic Safety Administration on ambulance safety for patients and providers", NHTSA Report, EMS World, pp. 91-94, 2015.

[2] Y. Moroi and K. Takami, "A method of securing priority-use routes for emergency vehicles using inter-vehicle and vehicle-road communication", IEEE 7th International Conference on New Technologies, Mobility and Security (NTMS), 2015.

[3] Osei-Ampofo, Oduro, Oteng, Donkor, Zakariah, \& Jacquet, "The Evolution and Current State of Emergency Care in Ghana. African Journal of Emergency Medicine, pp 52 - 58, 2013.

[4] S. Boslem, J. D. Moore and V. Charissis, "Investigating the Improvement of the Localisation Propensity and Impact of the Emergency Vehicle Sirens", in Proceedings of the Society of Automotive Engineers (SAE) World Congress 2011, 12-14 April, Detroit, Michigan, USA, 2011.

[5] V. Charissis, S. Papanastasiou, W. Chan, and E. Peytchev, "Evolution of a full-windshield HUD designed for current VANET communication standards", IEEE Intelligent Transportation Systems International Conference (IEEE ITS), The Hague, Netherlands, pp. 1637-1643, DOI: 10.1109/ITSC.2013.6728464, 2013.

[6] R. Lagoo, V. Charissis, W. Chan, S. Khan and D. Harrison, "Prototype gesture recognition interface for vehicular Head-Up Display system", IEEE International Conference on Consumer Electronics, Las Vegas, USA, pp.1-6, Jan. 2018.

[7] V. Charissis, and S. Papanastasiou, "Human-Machine Collaboration Through Vehicle Head-Up Display Interface", in International Journal of Cognition, Technology and Work, P. C. Cacciabue and E. Hollangel (eds.) Springer London Ltd Volume 12, Number 1, pp 41-50, DOI: 10.1007/s10111-008-0117, 2010.

[8] G. Weinberg, B. Harsham, and Z. Medenica, "Evaluating the usability of a head-up display for selection from choice lists in cars", 3rd International Conference on Automotive User Interfaces and Interactive Vehicular Applications, Automotive UI '11, pp. 39-46, ACM, 2011.

[9] J. D. Moore, S. Boslem, and V. Charissis, "Optimisation of Sound Localisation for Emergency Vehicle Sirens through Prototype Audio System", Book title: Design, User Experience, and Usability. Theory, Methods, Tools and Practice, Lecture Notes in Computer Science, J. A., Jacko (Ed), Vol. 6770, ISBN 978-3-642-21707-4, pp 177-186, Springer Berlin / Heidelberg, 2011.

[10] E. M. Wenzel, M. Arruda, D. J. Kistler, and F. L. Wightman, "Localisation using non-individualised head-related transfer functions", Journal of the acoustic society of America, Vol. 94, pp. 111-123, 1993.

[11] C. Ho and C. Spence, "Assessing the effectiveness of various auditory cues in capturing a driver's visual attention", Journal of experimental psychology: Applied, vol. 11, pp. 157-174, 2005.

[12] A. Dhani and D. Robineau, "Reported road casualties in Great Britain: quarterly provisional estimates year ending June 2018", Department of Transport, UK, 2018.

[13] G. Saunders and A. Gough, "Emergency Ambulances on the Public Highway Linked with Inconvenience and Potential Danger to Road Users", Emergency Medical Journal, Vol 20, pp 277-280, 2003.

[14] S. Wang, V. Charissis, R. Lagoo, J. Campbell, and D. K. Harrison, "Reducing Driver Distraction by Utilising Augmented Reality Head-Up Display System for Rear Passengers", IEEE International Conference on Consumer Electronics (IEEE ICCE), Las Vegas, USA, pp 1-6, DOI: 10.1109/ICCE.2019.8661927, 2019.

[15] S.Wang, V.Charissis, and D.Harrison, "Augmented Reality Prototype HUD for Passenger Infotainment in a Vehicular Environment", in Advances in Science, Technology and Engineering Systems Journal, Vol. 2, No. 3, 634-641 2017.

[16] H. Okumura, T. Sasaki, A. Hotta, and K. Shinohara, "Monocular hyperrealistic virtual and augmented reality display" 2014 IEEE Fourth
International Conference on Consumer Electronics (ICCE-Berlin), Berlin, Germany, pp.19-23, 2014

[17] H. Hsiao, J. Chang and P. Simeonov, "Preventing Emergency Vehicle Crashes: Status and Challenges of Human Factors Issues", Sage, Vol. 60 no. 7, pp. 1048-1072 https://doi.org/10.1177/0018720818786132, 2018.

[18] Fire (Scotland) Act 2005 - Scottish Parliament Bill, Legislation.gov.uk, 2005

[19] P. Albertsson and A. Sundström, "Evaluation of Insight Training of Ambulance Drivers in Sweden Using DART, a New E-learning Tool", Traffic Injury Prevention, pp. 621-629, ISSN: 1538-9588, 2011.

[20] S.S. Lam, F. N. Nguyen, Y.Y. Ng, V.P. Lee, T.H. Wong, S.M. Fook-Chong and M.E. Ong, "Factors affecting the ambulance response times of trauma incidents in Singapore", Accident; analysis and prevention, vol. 82, DOI: 10.1016/j.aap.2015.05.007, 2015.

[21] J. L. Gabbard, M. G. Fitch, K. Hyungil, "Behind the Glass: Driver Challenges and Opportunities for AR Automotive Applications", Proceedings of the IEEE, Vol. 102:2, pp.124-136, DOI: 10.1109/JPROC.2013.2294642, 2014.

[22] S.Wang, V.Charissis, J. Campbell, W.Chan, D. Moore and D.Harrison, "An investigation into the use of Virtual Reality technology for passenger infotainment in a vehicular environment, in International Conference on Advanced Materials for Science and Engineering (IEEE - ICAMSE), pp 404 - 407, DOI: 10.1109/ICAMSE.2016.7840359, Beijing, China, 2016.

[23] Y. Zeng, and N. Zhang, "Review and New Insights of the Traffic Flow Lattice Model for Road Vehicle Traffic Flow." Institute of Electrical and Electronics Engineers Inc., pp. 100-103, 2015.

[24] I. Prigogine, R. Herman, R, and R.S. Schechter, "Kinetic Theory of Vehicular Traffic." IEEE Transactions on Systems, Man, and Cybernetics Apr, pp. 295-295, 1972.

[25] M. L. L. Ianninia and R. Dickmanb, "Kinetic Theory of Vehicular Traffic", American Journal of Physics, Vol. 84, no. 135, https://doi.org/10.1119/1.4935895, 2016.

[26] B. G. Glaser and A. L. Strauss, "Discovery of Grounded Theory", New York: Routledge, https://doi.org/10.4324/9780203793206, 1999.

[27] S.M. Simons, A. Hicks, J. K. Caird, "Safety-critical event risk associated with cell phone tasks as measured in naturalistic driving studies: A systematic review and meta-analysis", Accident Analysis and Prevention Journal, Elsevier, Vol 87, pp 161-169, 2016.

[28] A. Gandhi, A. N. Hidayanto, Y. G. Sucahyo and Y. Ruldeviyani, "Exploring People's Intention to Become Platform-based Gig Workers : An Empirical Qualitative Study", IEEE 2018 International Conference on Information Technology Systems and Innovation (ICITSI), DOI: 10.1109/ICITSI.2018.8696017, 2018.

[29] H. Okumura, T. Sasaki, A. Hotta, A. Moriya, N. Okada and O. Nagahara, "Hyperrealistic head-up-display for automotive application", 2011 IEEE International Conference on Consumer Electronics (IEEE ICCE), DOI: 10.1109/ICCE.2011.5722913, 2011.

[30] H. Okumura, A. Hotta, T. Sasaki, K. Horiuchi, N. Okada, "Wide field of view optical combiner for augmented reality head-up displays, 2018 IEEE International Conference on Consumer Electronics (IEEE ICCE), DOI: 10.1109/ICCE.2018.8326064, 2018. 